Pak. j. sci. ind. res. Ser. A: phys. sci. 2019 62A(2) 76-81

\title{
Cloud Point Extraction for the Determination of Different Metal Ions by Using Bis(2-Acetyl Pyridine 4-Phenyl 3-Thiosemicarbazone) as Complexing Reagent
}

\author{
Ambreen Shah*, Fayyaz Ahmed Keerio, Saima Qayyum Memon and Ghulam Zuhra Memon \\ M. A. Kazi Institute of Chemistry, University of Sindh, Jamshoro, Sindh, Pakistan \\ (received April 26, 2018; revised January 24, 2019; accepted February 25, 2019)
}

\begin{abstract}
A new method of cloud point extraction was determined for preconcentration and determination of different metal ions like copper(II), nickel(II) and cobalt(II) ions. The complexation has been done by bis(2-acetyl pyridine 4-phenyl 3-thiosemicarbazone) (APPT) using sodium dodecyl sulphate (SDS) as surfactant. Metal ions are extracted into the phase rich in SDS after centrifugation. Initially, micellar phase was dissolved in $10 \mathrm{~mL}$ of deionized water then acidified with $0.5 \mathrm{~mol} / \mathrm{L} \mathrm{HNO}_{3}$, enhanced the surfactantrich phase and analyzed by flame atomic absorption spectrometry (FAAS). The effects of $\mathrm{pH}$, the concentrations of metal ions and chelating agent (APPT), volume of surfactant (SDS), equilibration temperature and time were studied on CPE. The preconcentration factor obtained was 25 and the limits of detection (DL) obtained for cobalt(II), nickel(II) and copper(II) were 1.5, 1.7 and $2.4 \mathrm{ng} / \mathrm{mL}$, respectively. This method of preconcentration was effectively useful for the determination of cobalt(II), nickel(II) and copper(II) in water samples.
\end{abstract}

Keywords: Bis(2-acetyl pyridine 4-phenyl 3-thiosemicarbazone) (APPT), sodium dodecyl sulphate, cloud point extraction; metal ions

\section{Introduction}

Copper has received significant importance due to its benefits in metallurgy and chemical industries. Copper is nutritionally one of the vital metals and is extensively spread in nature (Shokrolalin et al., 2008). Furthermore, it is a necessary element of about thirty enzymes and glyco-proteins and is required for the synthesis of hemoglobin and for some biological processes (Ghaedi et al., 2006a). Therefore, numerous methods for the determination of copper ion are accessible for metal ion determination at lower concentration which requires susceptible instrumental techniques and often a preconcentration step (Alan et al., 2007; Ghaedi, 2005b). Micelles and other organized amphiphilic assemble are increasingly helpful in analytical chemistry especially in separation and preconcentration procedures. These metal ions matrices samples are main source for some areas, for example environmental chemistry and food control. When levels of $\mathrm{Cu}$ exceed certain values, then the resistance mechanisms to protect against excess $\mathrm{Cu}$ are overcome and toxicity observed. Therefore, the heterogeneous structure of $\mathrm{Cu}$ along with different solute molecules can show strongly stable solubility,

*Author for correspondence;

E-mail: ambreen.shah@usindh.edu.pk chemical equilibrium, kinetics and the spectroscopic properties of compounds (Ghaedi, 2006c).

Nickel is the metal constituent and very essential for the enzyme activity. The toxicity of nickel needs more attention even in low concentration (Ghaedi, 2007; Quina, 1999). Cobalt, like nickel is also a toxic metal for the environment and obtained in the waste water of nuclear power and other industries waste as like electroplating, paints, pigments and electronic devices. Some scientists worked on the adsorption of $\mathrm{Ni}$ (II) and $\mathrm{Co}$ (II) ions complexation to acidic ion-exchanger resins (Kocaoba, 2008).

Separation methods are based on the nature of aqueous non-ionic and zwitterionic surfactant solution (Akhond, 2005; Stalikas, 2002). Aqueous solutions of almost all non-ionic surfactants become turbid when heated to a particular temperature known as the cloud point. On raising temperature, the isotropic micellar solution separates into two transparent liquid phases: a surfactant-rich phase which contains very small volume of surfactant and a small amount of water, and an aqueous phase, in equilibrium exists with the former (Kulichenko, 2003; Manzoori, 2002), which contains a surfactant concentration almost equal to the critical micellar concentration, is the mechanism of cloud point extraction 
(CPE) (Mostafavi, 2006; Nascentes, 2003). The small volume of the surfactant-rich phase was selected for this method, which is simple, cheap, highly efficient, and of lower toxicity to the environment than other extractions that use organic solvents. The CPE procedure has been used for the determination of extraction and pre-concentration of water soluble complexes with metal ions (Afzali, 2007; Alan, 2007; Gholivand, 2007). CPE has been shown as useful sample preconcentration technique for improving sensitivity and selectivity prior to atomic spectrometry (Lemos, 2006; Soylak, 2003; Silva, 2000).

Present work describes a simple, selective and sensitive cloud point extraction (CPE) method for pre-concentration on metal ions by atomic absorption spectrophotometer. This work also examined the determination of $\mathrm{Cu}(\mathrm{II}), \mathrm{Co}(\mathrm{II})$ and $\mathrm{Ni}(\mathrm{II})$ with preconcentration, in various real samples using bis[(2-acetyl pyridine) 4phenyl, 3-thio-semicarbazone (APPT) solution as selective and complexing agent.

\section{Materials and Methods}

Chemicals and samples. All chemicals were used of analytical grade. 2-acetyl pyridine, 4-phenyl 3-thiosemicarbazide (Fluka, Switzerland), sodium acetate, methanol, ethanol, acetone (E. Merck, Germany). Stock solutions (1000 mg/L) of $\mathrm{Cu}(\mathrm{II}), \mathrm{Co}(\mathrm{II}), \mathrm{Ni}(\mathrm{II})$ were prepared by direct dissolution of appropriate amounts of their respective sulphate salts. Sample solutions were freshly prepared by dilution from stock solution. Sodium dodecyl sulphate (SDS) solution $(0.1 \mathrm{~mol} / \mathrm{L})$ was prepared by dissolution into diluted sulphuric acid solution. Buffer solutions of 1-2, 3-6 and 7-9 were prepared by mixing appropriate ratios of $0.1 \mathrm{M} \mathrm{HCl}$ and $\mathrm{KCl}, 0.5 \mathrm{M}$ acetic acid and sodium acetate, $0.5 \mathrm{M}$ ammonia and $\mathrm{NH}_{4} \mathrm{Cl}$ solutions, respectively. This method is applied on real water samples, collected from river, and filtered through filter paper and stored in the refrigerator.

Instrumentation. Determinations of these three metal ions were carried out using the Perkin Elemer A. Analyst800 atomic absorption spectrophotometer. FTIR spectrum was recorded on Nicolet Avatar 330 FTIR with attenuated total reflectance (ATR) accessory (USA). The absorption and preconcentration were determined by flame atomic spectrophotometer, using air acetylene flame. Lamp current was $3 \mathrm{~mA}$ with slit width $0.5 \mathrm{~mm}$ for $\mathrm{Cu}$ (II), $0.2 \mathrm{~mm}$ for $\mathrm{Co}$ and $\mathrm{Ni}$ (II) ions. The wave lengths were also selected for maximum absorption such as 324.8 for $\mathrm{Cu}(\mathrm{II}), 240.7 \mathrm{~nm}$ for $\mathrm{Co}$ and $232 \mathrm{~nm}$ for $\mathrm{Ni}(\mathrm{II})$ metal ions, respectively.

Procedure for Preparation of bis[(2-acetyl pyridine) 4-phenyl, 3-thio semicarbazone] (APPT). The chelating agent used as complexation agent with different metal ions is bis(2-acetyl pyridine 4-phenyl 3-thiosemicarbizone) (APPT). It is prepared as:

One gram of 2-acetylpyridine was dissolved in $15 \mathrm{~mL}$ of de-mineralized double distilled water (DDW) and mixed in a flask with $50 \mathrm{~mL}$ of ethanol containing $0.8 \mathrm{~g}$ of 4-phenyl-3-thiosemicarbazide. The resulting solution was neutralized with sodium acetate and refluxed at $80{ }^{\circ} \mathrm{C}$ for $30 \mathrm{~min}$. It was allowed to cool to room temperature until yellow crystals were formed. These precipitates were separated and recrystallized from ethanol (M.P $\left.=220^{\circ} \mathrm{C}\right)$. The structural diagram is given in Fig. 1.

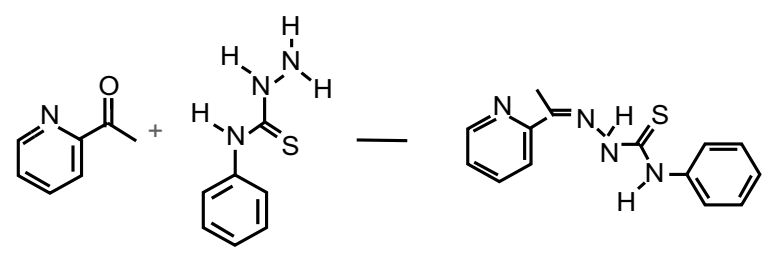

Fig. 1. Schematic diagram of bis(2-acetyl pyridine) 4-phenyl, 3-thiosemicarbazone (APPT).

Procedure for Cloud point extraction. A typical cloud point experiment required the following steps: An aliquot of $5 \mathrm{~mL}$ of a solution (100 ppm) containing $\mathrm{Cu}$ (II) ions, $0.5 \mathrm{~mL}$ APPT and $1 \mathrm{~mL}$ of SDS was adjusted to $\mathrm{pH} 8.0$ with an acetate buffer, then volume makeup to $50 \mathrm{~mL}$. The mixture was shaken for $1 \mathrm{~min}$ and left to stand in a thermo-stated bath at $60{ }^{\circ} \mathrm{C}$, for $10 \mathrm{~min}$. Separation of the phases was achieved by centrifugation at 4000 rpm, for $10 \mathrm{~min}$. The whole system was cooled in an ice-bath for $15 \mathrm{~min}$ so that the surfactant rich phase would regain its viscosity. In this way, the bulk aqueous phase was easily decanted. The remaining micellar phase was dissolved in $10 \mathrm{~mL}$ of deionized water and acidified with $0.5 \mathrm{~mol} / \mathrm{L} \mathrm{HNO}_{3}$ then the copper content was readily analyzed by flame atomic absorption spectrometry (FAAS). This procedure was also repeated with $\mathrm{Ni}$ (II) and $\mathrm{Co}$ (II) metal ions solutions at same conditions. 


\section{Results and Discussion}

Initially, the structure of bis[(2-acetyl pyridine) 4-phenyl, 3-thio semicarbazone] (APPT) can be confirmed by the C. H. N. elemental analysis (C; 69.2, H; 5.77, N; 11.57). After that the structure was further confirmed by using Infrared spectroscopy (FTIR) and U.V-visible spectroscopy. The FTIR spectrum showed all main characterized peaks such as $\mathrm{C}=\mathrm{N}$ bond at $1632 \mathrm{~cm}^{-1}, \mathrm{C}=\mathrm{S}$ at 1223 $\mathrm{cm}^{-1}$ and $\mathrm{N}-\mathrm{H}$ bond at $3270 \mathrm{~cm}^{-1}$, (Fig. 2).

Optimization of the CPE procedure. In order to obtain maximum extraction efficiency by CPE method, various factors need to be taken into account before analysis of the real samples. The most important are:

1) Effect of $\mathrm{pH}$ of the sample solution

2) Effect of metal ions concentration

3) Effect of APPT concentration

4) Effect of ligand (SDS) volume

5) Effect of equilibration temperature

6) Effect of centrifuge time.

Effect of pH of the sample solution. The effect of $\mathrm{pH}$ is very important and initial step of CPE method. Even similar metal ions of variable concentrations, varies the $\mathrm{pH}$ level. This study observed full range of $\mathrm{pH}$ values from 2-10 pH and results are given in Fig. 3. All the results are repeated thrice and the mean results show that the effect of $\mathrm{pH}$ the maximum absorbance of $\mathrm{Ni}$ and $\mathrm{Co}$ reaches at the $\mathrm{pH}$ of 4 , and $\mathrm{Cu}$ at $\mathrm{pH}$ 8.0.

Because of the lower $\mathrm{pH}$ value lower than 7.0, shows that ligands may exist in protonated form which decrease its solubility in hydrophobic phase. However, the increase in $\mathrm{pH}$ will increase hydroxyl concentration and lead to formation of hydroxide precipitations which would decrease the concentration of ions. Consequently, the affect of buffer amount was investigated. This may be attributed to that, the ionic strength, which can affect the metal-chelates formation in solution was magnified when the volume of buffer solution was increased. Thus, an aliquot of $1 \mathrm{~mL}$ of buffer solution is selected for all experimental samples.

Effect of metal ions concentration. Stock solutions $(1000 \mathrm{mg} / \mathrm{L})$ of different metal ions like $\mathrm{Cu}(\mathrm{II}), \mathrm{Co}(\mathrm{II})$ and $\mathrm{Ni}(\mathrm{II})$ were used to prepare different (1-5 ppm) solutions for the maximum level of CPE method.

It was observed that the high absorbance is achieved after 3-4 ppm solution and retained, also given in (Fig. 4).

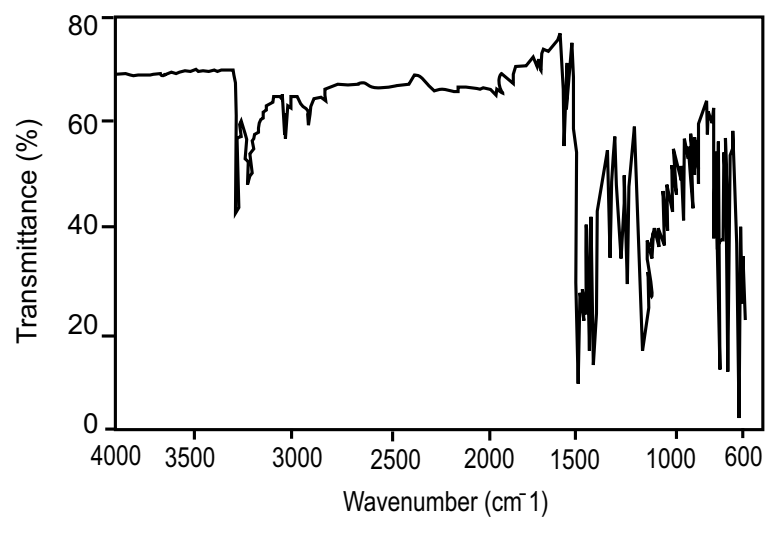

Fig. 2. FTIR spectrum of Bis(2-acetyl pyridine)4phenyl, 3-thiosemicarbazone (APPT).

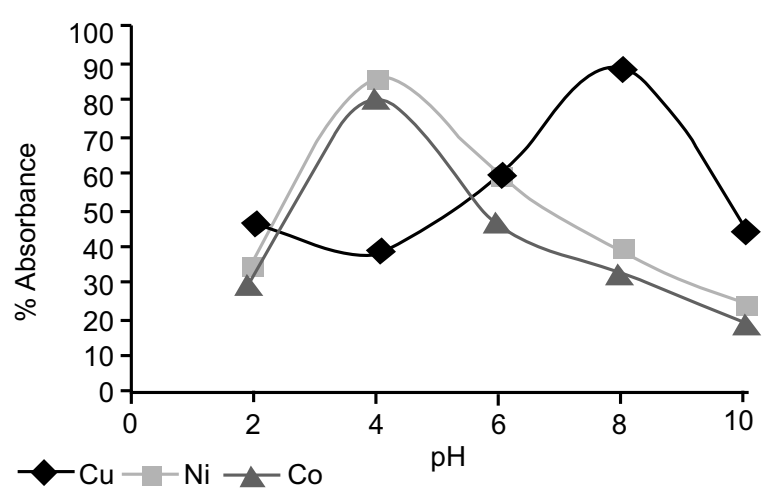

Fig. 3. Effect of $\mathrm{pH}$ of $\mathrm{Cu}(\mathrm{II}), \mathrm{Ni}(\mathrm{II})$ and $\mathrm{Co}(\mathrm{II})$ on CPE efficiency.

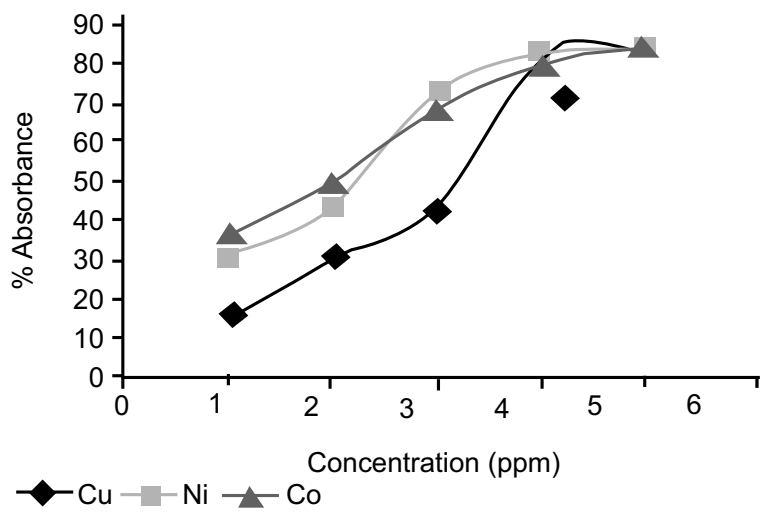

Fig. 4. Concentrations of $\mathrm{Cu}, \mathrm{Ni}$ and $\mathrm{Co}$ metals on CPE efficiency.

Effect of APPT concentration. Due to commercially low cost and low toxicological properties of APPT, it was selected for CPE method. As the surfactant rich 
phase facilitates phase separation by centrifugation, the cloud point of APPT permits its use in the preconcentration of sample solutions. The deviation on the extraction recovery, as a function of the APPT concentration is expressed in Fig. 5, when $50 \mathrm{~mL}$ solution containing cations and all the reagents in the presence of 0.25 $2.5 \%(\mathrm{w} / \mathrm{v})$ APPT was extracted.

The recovery is high as the APPT concentration was $0.5 \%(\mathrm{w} / \mathrm{v})$. At lower concentrations, the extraction efficiency of the complexes was low, due to the insufficiency of the assembly to entrap the metal ions. Hence, a concentration of $0.5 \%(\mathrm{w} / \mathrm{v})$ was selected.

Effect of (SDS) ligand volume. Sodium dodecyl sulphate (SDS) works as chelating reagents, having a specific interaction such as hydrogen bonding, between functional groups on the chelating reagents. In this work, sodium dodecyl sulphate (SDS) was used because it produces sufficiently hydrophobic complexes with most of metals. A $50 \mathrm{~mL}$ of $\mathrm{Cu}$ ions solution containing 20 $\mathrm{mg} / \mathrm{L}$ of the metal ion, $0.5 \%(\mathrm{w} / \mathrm{v})$ APPT, at a buffer of $\mathrm{pH} 8.0$ containing various amounts of SDS $(\mathrm{mol} / \mathrm{L})$, was chosen for the CPE method. It can be observed that the extraction recovery for the metal ions increases with increasing the ligands concentration and remains constant. The volume of SDS was ranged as $0.5,1.0$, 1.5, 2.0, $2.5 \mathrm{~mL}$ of SDS and $1 \mathrm{~mL}$ was selected for further study (Fig. 6).

Effect of equilibration temperature. The effect of equilibration temperature has greatest pre-concentration efficiency toward CPE process. In our work, the equilibration temperature of the thermostatic bath was adjusted within the range of $40-100{ }^{\circ} \mathrm{C}$ (Fig. 7). It is found that the equilibration temperature of $60-62^{\circ} \mathrm{C}$ is satisfactory for all the samples.

Effect of centrifugation time. As the equilibration temperature was optimized for the best result then the next step was the centrifugation time because it is also necessary how much time required to shack the samples with particular speed. For this purpose the centrifugation time was studied in the range of 5-25 min at $4000 \mathrm{rpm}$ (Table 1). An absolute separation observed with $10 \mathrm{~min}$ at $4000 \mathrm{rpm}$, is chosen as the optimal centrifugation time.

Analytical method (Preconcentration factor). The limit of detection (LOD) is defined as the concentration of analyte that gives a response equivalent to three times the standard deviation (SD) of the blank. The enrichment factor (EF) was calculated as the ratio of the slopes of the calibration curves obtained with and without preconcentration. The precision of the proposed method

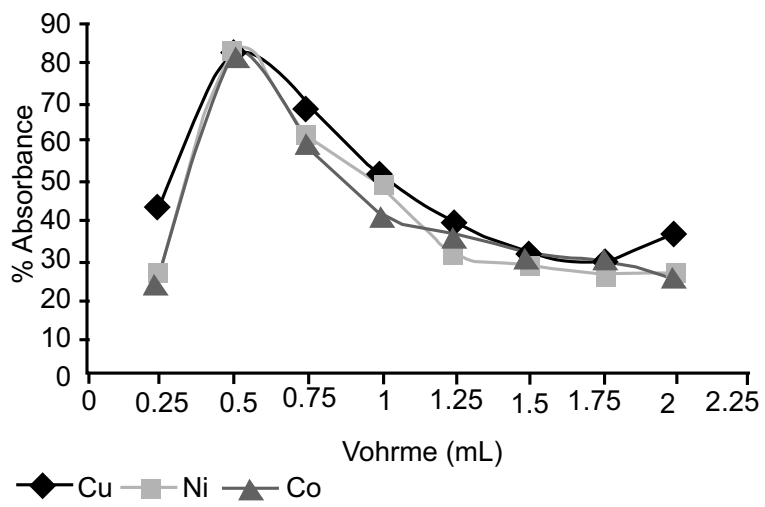

Fig. 5. Effect of APPT concentrations on $\mathrm{Cu}, \mathrm{Ni}$ and Co metal ions.

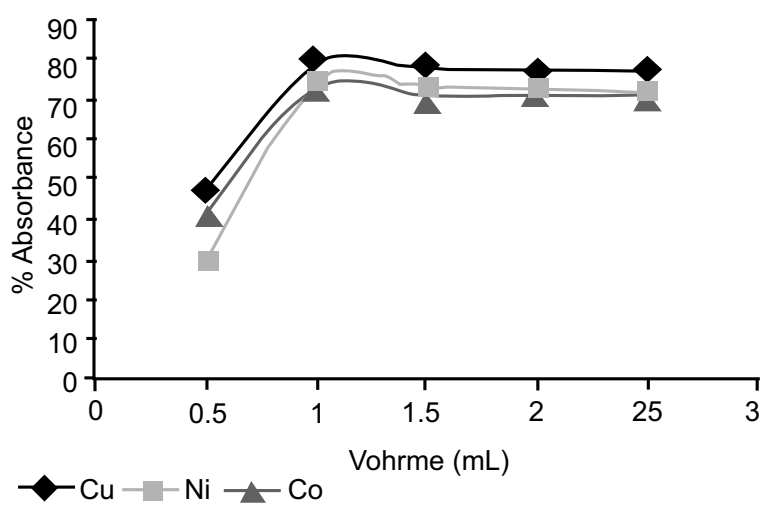

Fig. 6. Effect of (SDS) ligand volume of $\mathrm{Cu}, \mathrm{Ni}$ and Co metal ions.

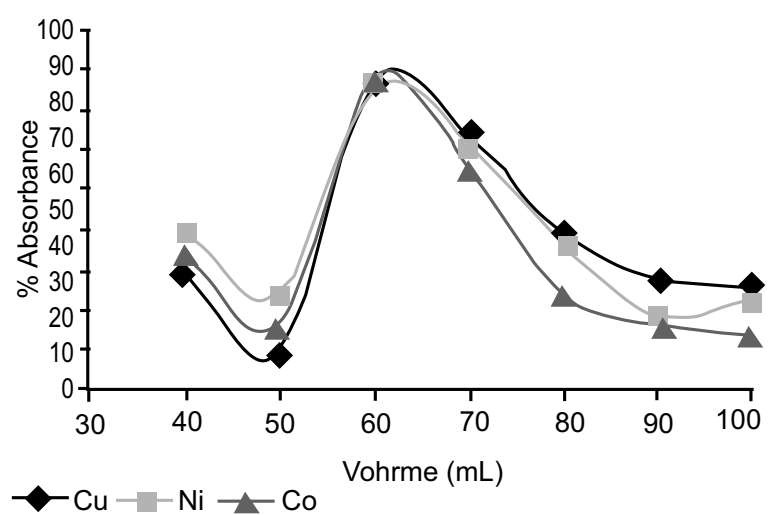

Fig. 7. Effect of equilibration temperature of $\mathrm{Cu}$, $\mathrm{Ni}$ and Co metal ions. 
Table 1. Effect of centrifugation time of $\mathrm{Cu}, \mathrm{Ni}$ and $\mathrm{Co}$ metal ions

\begin{tabular}{llll}
\hline \hline \multicolumn{4}{c}{ Effect of optimum centrifuge time } \\
\hline Time (min) & $\mathrm{Cu}$ (II) & Ni (II) & Co (II) \\
\hline 5 & 35 & 40 & 42 \\
10 & 85 & 80 & 83 \\
15 & 68 & 64 & 56 \\
20 & 45 & 30 & 22 \\
25 & 32 & 28 & 18 \\
\hline \hline
\end{tabular}

was evaluated as the preconcentration factor obtained was 25 and the limits of detection (DL) obtained for cobalt(II), nickel(II), and copper(II) were 1.5, 1.7 and $2.4 \mathrm{ng} / \mathrm{mL}$, respectively when $10.0 \mathrm{~mL}$ of sample was preconcentrated.

Pretreatment of samples. Analysis of water samples for determination of copper ions content was performed as following:

$400 \mathrm{~mL}$ of sample was poured in a beaker and $8 \mathrm{~mL}$ concentrated $\mathrm{HNO}_{3}$ and $3 \mathrm{~mL}$ of $30 \%$ (v/v) $\mathrm{H}_{2} \mathrm{O}_{2}$ for the removal of organic compounds, were added. The sample was mixed with continuous stirring and was heated to one tenth volume. After adjustment of samples $\mathrm{pH}$ to preferred value the $\mathrm{CPE}$ were performed according to general described procedure.

\section{Conclusion}

CPE offers much compensation over traditional liquidliquid extraction. Compared with traditional solvent extraction, CPE uses water and avoids the use of large amount of toxic and flammable organic solvents. In $\mathrm{CPE}$ method, optimized parameters of pre-concentration for $\mathrm{Co}(\mathrm{II}), \mathrm{Ni}(\mathrm{II}), \mathrm{Cu}(\mathrm{II})$ ions are determined by atomic absorption spectrophotometer. In addition, CPE can lead to higher recovery efficiency and a large preconcentration factor because the presence of surfactant can minimize losses of analytes due to their adsorption. The satisfied results of application to real water samples indicate that the CPE method allows analytes determination with good accuracy and excellent results.

Conflict of Interest. The authors declare no conflict of interest.

\section{References}

Afzali, D., Mostafavi, A., Taher, M.A., Moradian, A. 2007. Flame atomic absorption spectrometry determination of trace amounts of copper after separation and preconcentration onto TDMBACtreated analcime pyrocatechol-immobilized. Talanta, 71: 971-975.

Akhond, M., Ghaedi, M., Tashkhourian. 2005. Development of a new copper(II) ion-selective poly (vinyl chloride) membrane electrode based on 2-mercaptobenzoxazole. Bulletin-Korean Chemical Society, 26: $882-886$.

Alan, M., Kara, D., Fisher, A. 2007. Preconcentration of heavy metals and matrix elimination using silica gel chemically modified with 2, 3-Dihydroxybenzaldehyde. Seperation Science and Technology, 42: 879-895.

Ghaedi, M. 2007. Selective and sensitized spectrophotometric determination of trace amounts of $\mathrm{Ni}(\mathrm{II})$ ion using alpha benzyl dioxime in surfactant media. Spectrochimica Acta Part A: Molecular and Biomolecular Spectroscopy, 66: 295-301.

Ghaedi, M., Ahmadi, F., Karimi, H., Gharaghani, S. 2006a. Preconcentration and extraction of copper on activated carbon using 4-amino-2, 3-dimethyl1-phenyl-3-pyrazoline or 4-(4-methoxybenzylidenimin thiophenol. Journal of the Korean Chemical Society, 50: 23-31.

Ghaedi, M., Asadpour, E., Vafaie, A. 2006b. Simultaneous preconcentration and determination of copper, nickel, cobalt, lead and iron content using a surfactant-coated alumina. Bulletin of the Chemical Society of Japan, 79: 432-436.

Ghaedi, M., Shokrollahi, A. 2006c. Chromosorb, an alternative suitable support for trace copper ion enrichment using 2-mercaptobenzoxazole as modifier. Feressenius Environmental Bulletin, 11: 1373-1381.

Ghaedi, M., Fathi, M.R., Marahel, F., Ahmadi, F. 2005. Simultaneous preconcentration and determination of copper, nickel, cobalt and lead ions content by flame atomic absorption spectrometry. Feressenius Environmental Bulletin, 14: 1158-1163.

Gholivand, M.B., Ahmadi, F., Rafiee, E. 2007. Solid phase extraction and determination of ultra trace amounts of copper using activated carbon modified by N,N'-Bis(Salicylidene)-1,2-Phenylenediamine. Separation Science and Technology, 42: 897-910.

Kocaoba, S. 2008. Adsorption of $\mathrm{Ni}(\mathrm{II})$ and $\mathrm{Co}(\mathrm{II})$ ions and application of surface complex formation model to ion exchange equilibria. Environmental Engineering Sciences, 25: 697-702. 
Kulichenko, S.A., Doroschuk, V.O., Lelyushok, S.O. 2003. The cloud point extraction of copper(II) with monocarboxylic acids into non-ionic surfactant phase. Talanta, 59: 767-773.

Lemos, V.A., Santos, J.S., Baliza, P.X. 2006. Me-BTABr reagent in cloud point extraction for spectrometric determination of copper in water samples. Journal of Brazilian Chemical Society, 17: 30-35.

Manzoori, J.L., Bavili-Tabrizi, A. 2002. The application of cloud point preconcentration for the determination of $\mathrm{Cu}$ in real samples by flame atomic absorption spectrometry. Microchemical Journal, 72: 1-7.

Mostafavi, A., Afzali, D., Taher, M.A. 2006. Atomic absorption spectrometric determination of trace amounts of copper and zinc after simultaneous solid-phase extraction and preconcentration onto modified natrolite zeolite. Analytical Sciences, 22: 849-853.

Nascentes, C.C., Arruda, M.A. 2003. Cloud point formation based on mixed micelles in the presence of electrolytes for cobalt extraction and preconcentration. Talanta, 61: 759-768.

Quina, F.H., Hinze, W.L. 1999. Surfactant-mediated cloud polint extractions: An environmentally benign alternative separation approach. Industrial and Engineering Chemical Research, 38: 4150-4168.

Shokrolahi, A., Ghaedi, M., Gharaghani, S.H., Fathi, M.R., Soylak, M. 2008. Cloud point extraction for the determination of copper in environmental samples by flame atomic absorption spectrometry. Quimica Nova, 31: 70-74.

Silva, M., Andreia, M., Frescura, A., Lucia, V., Curtius, A.J. 2000. Determination of trace elements in water samples by ultrasonic nebulization inductively coupled plasma mass spectrometry after cloud point extraction. Spectrochimica Acta, Part-B, Atomic Spectroscopy, 55: 803-813.

Soylak, M., Karatepe, A.U., Elci, L., Dogan, M. 2003. Column preconcentration/separation and atomic absorption spectrometric determinations of some heavy metals in table salt samples using amberlite XAD-1180. Turkish Journal of Chemistry, 27: 235-242.

Stalikas, C.D. 2002. Micelle-mediated extraction as a tool for separation and preconcentration in metal analysis. Trends in Analytical Chemistry, 21: 343-355. 